\title{
Endovascular occlusion of uterine arteries in the treatment of symptomatic uterine leiomyoma
}

\author{
${ }^{1}$ Head of the department of Radiology, «UMC», National \\ Research Center of Maternity and Child Health, Astana, \\ Kazakhstan. \\ ${ }^{2}$ Head of the Department of Radiology named after \\ academician Zh. Kh. Khamzabaev, JSC "MUA", Astana. \\ Kazakhstan. \\ ${ }^{3}$ Head of the department of Radiology, «UMC» National \\ Diagnostics Center, Astana, Kazakhstan.
}

Abishev Bakhyt ${ }^{1}$, Rakhimzhanova Raushan ${ }^{2}$, Tazhibaeyv Dulat ${ }^{3}$.

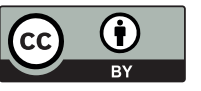

This work is licensed under a

Creative Commons Attribution 4.0

International License

J CLIN MED KAZ 2017; 3(45 SUPPL 3):11-13 Автор для корреспонденции: Тажибаев Д.М., Отдел лучевой диагностики, КФ «UMC» Республиканский Диагностический Центр, Астана, Казахстан. Ул. Сыганак 2, Астана, Казахстан. 8 70132850 51. Tazhibaev74@mail.ru.

\section{ABSTRACT}

Objective:assess the condition of the uterus and myomatous nodes after EMA in different periods by ultrasound and MRI.

Methods. EMA was performed in 632 patients with various forms of uterine fibroids. To achieve this goal, 120 observations with various forms of uterine fibroids were analyzed.

Results. Reduction of myomatous nodes according to ultrasound and MRI in 1 month was - 18.4-17.3\%, after 3 months - 40.7-42.9\%, after 6 months it was - 60.4-61.8\% and through 12 months $-72.5-74.7 \%(\mathrm{p}<0.05)$ respectively. Necrotic isolation of the node, expulsion of myomatous nodes and removal of the partially submucous node giving birth was observed in n-18 (15\%) cases. In n-12 (10\%) observations, after uterine artery embolization, laparoscopic myomectomy of the subserousmyomatous nodes was performed.

Conclusion. our experience shows that EMA is highly effective method for treating uterine fibroids, performed depending on various forms alone or in combination with operational accommodation.

Keywords:Embolization of uterine arteries - X-ray endovascular occlusion magnetic resonance imaging-myoma of the uterine myomatous nodes.

\section{ТҰЖЫРЫМДАМА}

СИМПТОМДЫҚ ЖАТЫР МИОМАСЫН ЕМДЕУДЕГІ РЕНТГЕНЭНДОВАСКУЛЯРЛЫҚ ЖАТЫР АРТЕРИЯЛАРЫНЫН ОккЛЮзИясы.

Әбішев Б.Х.1, Рахымжанова P.І. ${ }^{2}$, Тәжібаев Д. М. ${ }^{3}$

'Сәулелек диагностика бөлімінің менгерушісі, КҚ «UMC» Ана мен Бала Ұлтық Ғылыми Орталығы, Астана, Қазақстан.

${ }^{2}$ «АМУ» АҚ, академик Ж.Х. Хамзабаев атындағы радиология кафедрасының менгерушісі, Астана, Қазақстан.

${ }^{3}$ Сәулелек диагностика бөлімінің менгерушісі, КҚ «UМC» Республикалық Диагностика Орталығы, Астана, Қазақстан.

Мақсаты: УМЗ кейін әртүрлі кезеңдерде жатыр мен миоматозды түйіндердің жағдайын Удз мен МРТ арқылы бағалау.

Зерттеудің әдістері: ЕМА әртүрлі жатыр миомасы бар 632 науқаста орындалды. Осы мақсатқа жету үшін ана миомасының түрлі нысандары бар 120 байқау талданды.

Нәтижелері: Миоматозды түйіндерді ультрадыбыстық және ЕРТ бойынша 1 ай ішінде азайту - 18,4-17,3\%, 3 айдан кейін - 40,7-42,9\%, 6 айдан кейін - 60,4-61,8\% 12 ай - тиісінше 72,5-74,7\% (p00,05).

N-18 (15\%) жағдайында түйінді тітіркендіргіш оқшаулау, миоматозды түйіндерді алып тастау және ішінара субмукозды түйінді босату. В-12 (10\%) байқауында жатырдың артерия эмболизациясынан кейін миоматозды тораптардың лапароскопиялық миомектомиясы орындалды.

Қорытынды: біздің тәжірибеміз көрсеткендей, ЕМА - әртүрлі нысандарға немесе операциялық тұрғыдан үйлесімге байланысты орындалатын, жатыр миомасын емдеуде органды сақтаушы, жоғары тиімді әдіс.

Маңызды сөздер: Жатыр артерияларының эмболизациясы - рентгендік эндоваскулярлы окклюзия- магнитті резонансты бейнелеу миоматозды түйіндердің миомасы. 


\author{
PEЗЮМЕ \\ РЕНТГЕНЭНДОВАСКУЛЯРНАЯ ОККЛЮЗИЯ МАТОЧНЫХ АРТЕРИЙ В ЛЕЧЕНИИ СИМПТОМНОЙ МИОМЫ \\ МАТКИ \\ Абишев Б.Х. ${ }^{1}$, Рахимжанова Р. И. ${ }^{2}$, Тажибаев Д.М. ${ }^{3}$ \\ ॐаведующий отделением лучевой диагностики, КФ «UMC» Национальный Научный Центр Материнства и Детств, Астана, Казакстан. \\ 2Заведующий кафедрой радиологии имени академика Ж. Х. Хамзабаева, АО «МУА», Астана. Казахстан. \\ 3Заведующий отдела лучевой диагностики, КФ «UMC» Республиканский Диагностический Центр, Астана, Казахстан.
}

Цель исследования: оценить состояние матки и миоматозных узлов после ЭМА в различные сроки методами УЗИ и МРТ.

Материалы и методы: ЭМА было выполнено у 632 пациенток с различными формами миомы матки. Для достижения поставленной цели было проанализировано 120 наблюдений с различными формами миомами матки.

Результаты:Уменьшение миоматозных узлов по данным УЗИ и МРТ в 1 месяц составил - 18,4-17,3\%, через 3 месяца - 40,7-42,9\%, через 6 месяца составил - 60,4-61,8\% и через 12 месяцев - 72,5-74,7\% (p<0,05) соответственно.

Некротическое выделение узла, экспульсия миоматозных узлов и удаление частично рождающего субмукозного узла наблюдалось в n-18 (15\%) случаях. В n-12 (10\%) наблюдениях, после эмболизации маточных артерий было выполнено лапороскопическая миомэктомия субсерозных миоматозных узлов.

Выводы: наш опыт свидетельтвует что ЭМА является органосохраняющим, высокоэффективным методом лечения миомы матки, выполняемым в зависимости от разных форм самостоятельно или в комбинации с оперативным вмещательством.

Ключевые слова: Эмболизация маточных артерий- рентгеноэндоваскулярная окклюзия-

магнитно-резонансная томография- миома матки- миоматозные узлы.

\section{Введение}

Миома матки является одной из наиболее распространенных опухолевых заболеваний женских половых органов. Частота встречаемости этого заболевания по данным аутопсийного материала колеблется от 70 до $85 \%$. Симптомная миома матки в возрасте от 20 до 30 лет встречается у 5-7\% женщин, в 30-40 летнем возрасте у 20-25\% женщин, достигших пременопаузального возраста частота лейомиом достигает 30$35 \%$, а по данным некоторых авторов и до 40\% [1, 2, 3].

Эмболизация маточных артерий (ЭМА) при миоме, предложенная J.Ravina в 1994году, положила основу для развития нового органосохраняющего внутрисосудистого метода лечения этой распространенной гинекологической патологии.

\section{Материалы и методы}

Миома матки является одной из наиболее распрЧерезкожная черезкатетерная ЭМА как метод лечения миомы матки проводилось 632 пациенткам. Возраст пациенток колебался от 20 до 50 лет, средний возраст 35,5 лет.Исходный диаметр миоматозных узлов по данным УЗИ и по данным МРТ составил от 3,0 до 14,0см. У 449 женщин (71\%) наблюдалось множественные миомы и у 183 (29\%) пациенток одиночный узел.

Субмукозная форма при МРТ и УЗИ обследований выявлена у 57 женщин (9\%), интерстициальная форма - у 189 женщин (29,9\%), и смешанная форма - у 386 женщин $(61,1 \%)$.

Всем больным проведен комплекс лабораторноинструментальных методов исследований.

Первичная визуализация и последующее наблюдение за изменениями объема матки, миоматозных узлов и структуры миоматозных узлов осуществлялись по данным ультразвукового и магнитно-резонансного исследований.

\section{Результаты и обсуждение}

Для достижения поставленной цели нами было проанализировано 120 наблюдений с различными формами миомами матки. Все больные находились на стационарном лечении в АО «Национальный Научный Центр Материнства и Детства».

По данным литературных источников двухсторонняя эмболизация маточных артерий выполняется удачно у 96$100 \%$ пациенток. В редких случаях, суперселективную катетеризацию и эмболизацию одной из артерий выполнить не удается [4].
В нашей работе суперселективная билатеральная катетеризация маточных артерий выполнена в 98,9\%. Односторонняя эмболизация на стороне доминирующего кровоснабжения миоматозного узла выполнена у одной пациентки. В одном наблюдений при тазовой артериографии, маточная артерия с одной стороны, не визуализировалась, и было выполнена монолатеральная эмболизация. В обоих случаях монолатеральная ЭМА оказалось эффективной, при динамическом наблюдений на УЗИ и МРТ. Такой феномен объясняется аностомозированием сосудов и попаданием окклюзирующих материалов в артериальную систему контрлатеральной стороны при перераспределении кровотока во время процедуры эмболизации [5].

При трансфеморальном доступе, в данной работе, у одной пациентки после ЭМА выявлена диссекция на уровне пункции и в одном наблюдении отмечался ангиоспазм сосудов нижней конечности на стороне пункции (1,0\%). Осложнения этой категории встречается и в других публикациях. Гематома места пункции, перфорация артерий и диссекция интимы встречается от $1,6 \%$ до 3,2\% [6, 7, 8].

Для внутрисосудистой эмболизации маточных артерий, нами использовалась частицы ПВА и микросферы 355$1500 \mathrm{MKн.}$

ЭМА считалась завершенной при остановке кровотока по маточным артериям или при остановке кровотока в дистальных отделах маточной артерии. По литературным данным $[9,10]$ для эффективной эмболизации и ретроградного сброса эмболизирующего материала в близлежащие ветви внутренней подвздошной артерии необходимо довести кончик катетера до уровня L-образного изгиба маточной артерии и достичь эффекта «стоп-контраст» по маточным артериям.

После внутрисосудистого вмешательства уменьшение болевого синдрома связанного с миомами матки, нормализация длительности менструации и кровотечения при менструации и других симптомов, связанных с миомами матки наблюдались у 95,4\% пациенток. По данным некоторых авторов [6, 11] симптомы, связанные с миомой матки после эндоваскулярной окклюзии уменьшаются до 75-96\%.

По даннымнекоторых авторов уменьшение объема миоматозных узлов на сроках $1-6$ месяцев после ЭМА составляет $27-70 \%[1,12]$.

По нашим данным (n-90) уменьшение миоматозных узлов по данным УЗИ и МРТ в 1 месяц составил - 18,4-17,3\% $(\mathrm{p}<0,05)$, через 3 месяца - 40,7-42,9\% $(\mathrm{p}<0,05)$, через 6 месяца 
составил - 60,4-61,8\% (p<0,05) и через 12 месяцев - 72,5-74,7\% $(\mathrm{p}<0,05)$ соответственно.

По МР-изображениям в динамике наблюдается уменьшение диаметра, деформация миоматозного узла, изменения интенсивности МР-сигнала миоматозного узла. Уменьшение объема матки прямо пропорционально уменьшению объема миоматозных узлов.

Выделение фрагментов некротизированных узлов многие авторы расценивают, как осложнение после проведенного внутрисосудистого вмешательства. Данное осложнение по их данным встречается в 5-6\%, преимущественно, при субмукозном расположений узлов $[6,13]$. В нашей работе некротическое выделение узла, экспульсия миоматозных узлов и удаление частично рождающего субмукозного узла наблюдалось в n-18 (15\%) наблюдениях. Черезвлагалищную экспулсию подслизистых узлов S.Abbara c соавт. (1999) считает наиболее радикальным эффектом внутрисосудистой терапии миомы. После экспульсии миоматозного узла восстанавливается топография полости матки.

В нашей работе n-12 (10\%) наблюдениях после ЭМА на вторые сутки с целью предотвращения отшнуровывания субсерозных миоматозных узлов была выполнена лапороскопическая миомэктомия. Интероперационная кровопотерия при этом составило 50-80мл.
По данным некоторых авторов[1, 8] кровопотеря при миомэктомии без предварительной ЭМА составляет 500800мл.

Классическим способом лечения и единственным радикальным методом устранения миомы на данном этапе является гистерэктомия. Консервативная миомэктомия или лапороскопическое удаление миом позволяют, сохранит репродуктивный орган, но являются технический более сложными. Сроки реабилитации после консервативной и лапораскопической миомэктомии намного больше чем после ЭМА.

\section{Выводы}

Наш опыт свидетельтвует чтоЭМА является органосохраняющим, высокоэффективным методом лечения миомы матки, выполняемым в зависимости от разных форм самостоятельно или в комбинации с оперативным вмещательством. Уменьшение или полное исчезновение клинических проявлений миомы матки отмечается после эмболизации у 95,4\% больных. Уменьшение объема миоматозных узлов в течении года по данным УЗИ и МРТ достигает 72,5-74,7\%. Предоперационная ЭМА способствует снижению интероперационной кровопотери.

\section{Литература}

1. Olive D. Revitw of the evidence for treatment of leiomyomata. Environmental Health Perspectives.2000;108 (5):841 - 843.

2. Duhan N. Current and emerging treatments for uterine myoma - an update. Int. J. Womens Health. 2011 ; (3): 231 - 41.

3. Isonishi S., Coleman R., Hirama M. et al. Analysis of prognostic factors for patients with leiomyoma treated with uterine arterial embolization.Am. J. Obstet. Gynecol. 2008;(19): 270-278.

4. Goodwin S., Vedantham S., McLucas B. et al. Preliminary experience with uterine artery embolization for uterine fibroids.J. Vasc. Intervent. Radiol.1997. (8):517-526.

5. Worthington-Kirch R. L. Flow redistribution during uterine aftery embolization for the management of symptomatic fibroids. J.Vasc. Intervent. Radiol.1999; (10): 237-238.

6. Spies J. B., Ascher S. A., Goodwin S. Uterine Artery Embolization for Leiomyomata. Obstet. End Gynecol. 2001; (98):29 - 34.

7. Brunereau L., Herbreteau D., Gallas. Et al. Uterine artery embolization in the primary treatment of uteribe leiomyomas: Technical feartures and hrospertive follow-up with clinical and sonographic examination in 58 pacients. Amer. J. Roentgen ol.2000;(175):1267-1272.

8. Toor S.S., Jaberi A., Macdonald D.B., Mclnnes M.D., Schweitzer M.E., Rasuli P. Complication rates and effectiveness of uterine artery embolization in the treatment of symptomatic leiomyomas: a systematic review and meta-analysis. AJR Am. J. Roentgenol.2012; (199): 1153-63.

9. Vedantham S., Gooswin S., McLucas B. Uterin artery embolization: Am. J. Obstet. Gynecol. 1997;(176): $938-948$.

10. B.Bobrov, S.Kapranov, V.Breusenko, Yu.Dobrokhotova, I.Krasnova, V.Aksenova, D.Aryutin. Uterine artery embolization: a modern view of the problem.Diagnosticand InterventionalRadiology.2007; 1.1 (2):56-70.

11. Lumsden M. Embolization versus meomectomy versus hysterectomy: Which is best, when? Hum. Reprod.2002. 1.17(2): 253259.

12. Horhoianu I.A., V Horhoianu V.V , Joita D., Carstoiu M., Dorobat B.Uterine artery embolization for leioyomas, ultrasonography and angiography aspects. J. Med Life.2012; 5(4):491-5.

13. Hutshins F., Worthington-Kirch R., Berkowitz R. Selective uterine artery embolization as primary treatment for symptomatic leiomyomata uteri: Areview of 305 consecutive cases. J. Amer. Assoc. Gynecol. Laparosc. 1999; (6): 279-289.

14. Abbara S., Spies J., Scaialli A. et al. Transcervical expulsion of fibroids result of uterine artery embolization of leiomyomata. J. Vasc. Intervent. Radiol. 1999; (10): 409-411. 